\title{
Akses Kontrol Kotak Kunci Ruang Kelas Berbasis Smartphone Android
}

\author{
Muhammad Arifin ${ }^{1,2 *}$, Egi Fazar Firrizqi ${ }^{1}$ dan Abdullah Sani ${ }^{1}$ \\ ${ }^{1}$ Departemen Teknik Elektro, Politeknik Negeri Batam, Batam 29461 Indonesia \\ ${ }^{2}$ Teaching Factory Manufacturing of Electronics (TFME), Politeknik Negeri Batam, Batam 29461 \\ Indonesia \\ "E-mail: arifin@ polibatam.ac.id
}

\begin{abstract}
Abstrak
Perkembangan Android menjadi sebuah sistem operasi pada smartphone sudah banyak digunakan hampir di seluruh penjuru dunia. Sistem operasi android ini juga merupakan merupakan sistem operasi berbiaya murah. Pemanfaatan sistem operasi android bersamaan dengan mikrokontroler mempunyai banyak kegunaan. Salah satu kegunaannya adalah diaplikasikan sebagai kotak tempat penyimpanan kunci sehingga dengan memanfaatkan sistem operasi android monitoring pengguna/peminjam kunci dapat dilakukan dengan mudah. Pengujian yang dilakukan pada perangkat yang dibuat meliputi pengujian aplikasi, pengujian aplikasi terhadap perangkat keras, dan pengujian tampilan data di website. Hasil dari pengujian fungsi menunjukkan bahwa kotak tempat penyimpanan kunci bekerja secara baik dan monitoring menggunakan website sudah bisa lakukan sehingga data dari monitoring yang didapat adalah real time.
\end{abstract}

Kata kunci: Kotak kunci ruang kelas, smartphone android, data real time.

\begin{abstract}
Recently, many smartphones have applied Android as their operating system (OS). OS Android has many advantages such as available for many kind of smartphone, cheap, and so on. If OS Android and microcontroller system are joined, it will have more advantages and applications. One of its applications is the automatic key for smart storage box. The data of key's user can be monitored easily using this smart storage box. In this research was carried out some examinations for smart storage box such as examining application against hardware, and the data display in website. The results of function examinations show that smart storage box worked successfully and monitoring data in website can also be conducted well with real time.
\end{abstract}

Keyword: smart storage box for class room, android smartphone, real time data.

\section{PENDAHULUAN}

Dewasa ini perkembangan teknologi sangat pesat salah satunya pada bidang otomasi. Hampir semua mesin sekarang sudah serba otomatis baik di industri maupun dunia pendidikan (1-3). Perkembangan teknologi otomasi didasari dengan munculnya sistem mikroprosesor atau mikrokontroler (4). Mikrokontroler yang ada saat ini sudah mempunyai banyak tipe mulai dari yang sederhana hingga yang canggih. Jika dikembangkan oleh orang-orang yang ahli maka peralatan elektronika dapat membantu dalam kehidupan sehari-hari (5).

Perkembangan Android menjadi sebuah sistem operasi telepon pintar yang paling banyak digunakan di dunia. Sistem Android merupakan pilihan bagi perusahaan yang menginginkan sistem operasi berbiaya rendah (6). Sistem kontrol android dengan memanfaatkan mikrokontroler juga sudah dilakukan oleh Pahuja, dkk. Sistem android ini diaplikasikan di beberapa devais elektronik seperti robot (7), kunci pintu (8), pintu gerbang (9), dan devais elektronik lainnya. Selain itu, sistem keamanan juga termasuk hal yang perlu diperhatikan. Dalam sistem operasi android, keamanan merupakan sesuatu yang sangat penting dan merupakan sistem proteksi wajib (10).

Sebagian besar ruang kelas untuk mahasiswa jurusan Teknik Elektro, Politeknik Negeri Batam tersebar di beberapa gedung dan lantai. Salah satu ruangan kelas yang digunakan oleh mahasiswa jurusan Teknik Elektro adalah ruang kelas yang ada di gedung utama Polibatam lantai 1 . Semua pintu di ruang kelas tersebut masih menggunakan kunci manual sehingga ketika kelas akan dimulai, dosen atau mahasiswa harus mengambil kunci dan 
mengajar lainnya di gedung utama Polibatam lantai 4 atau Satpam. Kondisi ini kurang efisien bagi kegiatan belajar mengajar sehingga perlu adanya tempat penyimpanan kantung kunci di setiap ruang kelas. Untuk mengurangi permasalahan tersebut maka diperlukan tempat penyimpanan kantong kunci yang bisa diakses menggunakan smartphone dan database penggunanya juga bisa dimonitoring setiap saat.

\section{SISTEM YANG DIGUNAKAN}

Dalam penelitian dilakukan sistem yang digunakan terdiri dari perangkat keras (hardware), elektrikal, dan perangkat lunak (software). Perangkat keras yang digunakan dalam penelitian ini meliputi power supply, mikrokontroler arduino uno, relay, modul bluetooth, magnetic lock, dan handphone android. Adapun block diagram untuk perangkat keras yang digunakan ditunjukkan pada Gambar 1.

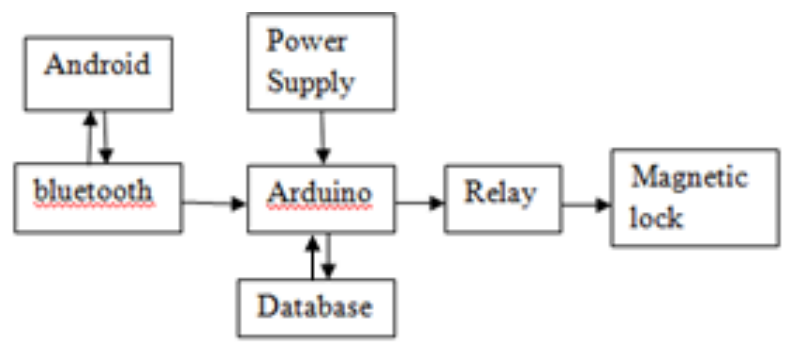

Gambar 1. Block diagram perangkat keras.

Perancangan elektrikal atau wiring untuk sistem yang dibuat seperti ditunjukkan pada Gambar 2. Wiring merupakan sesuatu yang penting karena juga menjadi salah satu faktor jalan atau tidaknya sistem yang dibuat.

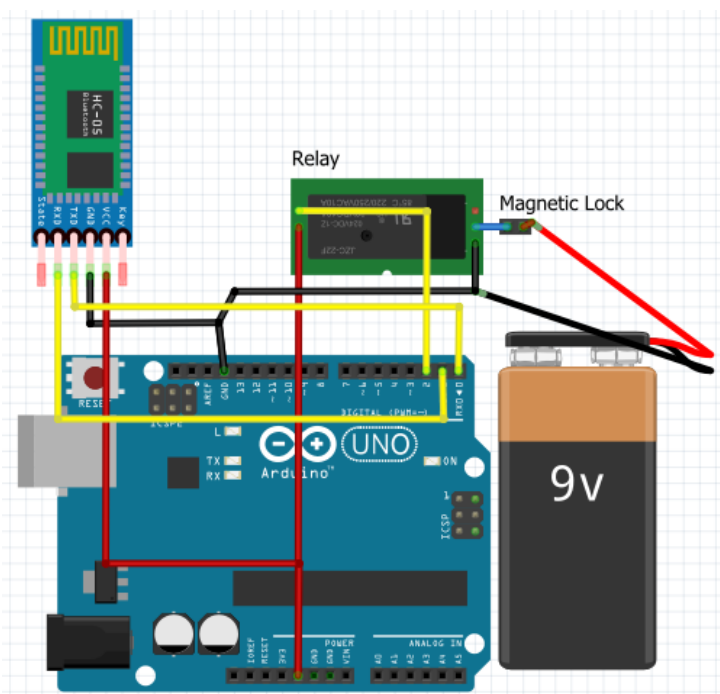

Gambar 2. Perancangan elektrikal atau wiring pada sistem.
Selain perangkat keras dan perancangan elektrikal, bagian mekanik juga merupakan bagian yang penting. Pemilihan bahan dan desain mekanik dari perangkat yang dibuat juga menentukan kualitas serta efisiensi perangkat. Tampilan mekanik dari kotak penyimpanan kunci seperti ditunjukkan pada Gambar 3. Desain mekanik ini memberi informasi mengenai bentuk dan ukuran kotak penyimpanan serta letak perangkat kontrolnya.

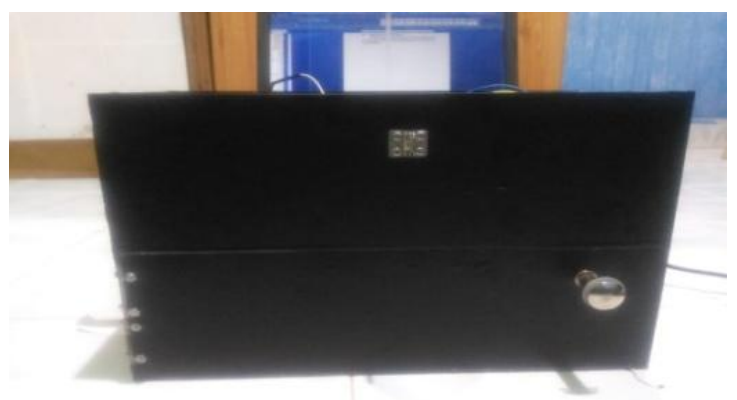

Gambar 3. Tampilan mekanik dari kotak penyimpanan kunci.

Alur kerja dari kotak penyimpanan berbasis android ini ditunjukkan pada diagram alir Gambar 4. Diagram alir ini menggambarkan alur kerja sistem alat atau perangkat yang dibuat.

Alur proses penggunaan tempat penyimpanan kotak kunci berbasis android dimulai dengan registrasi pengguna menggunakan smartphone android dengan memasukkan data yang diminta. Setelah registrasi berhasil, pengguna melakukan login. Jika login berhasil, maka akan dilakukan pengiriman data ke database oleh sistem. Proses dalam membuka kotak kunci digunakan bluetooth sebagai sarana komunikasi antara android dan perangkat keras (kotak penyimpanan). Jika bluetooth sudah terhubung, pengaktifan relay pada kota penyimpanan kunci sudah bisa dilakukan menggunakan menu yang ada di smartphone android. Menu ini sudah dibuat sebelumnya. Pada saat menaruh kunci kembali ke kota penyimpanan, alur prosesnya sama dengan pengambilan kunci di dalam tempat penyimpanan. 


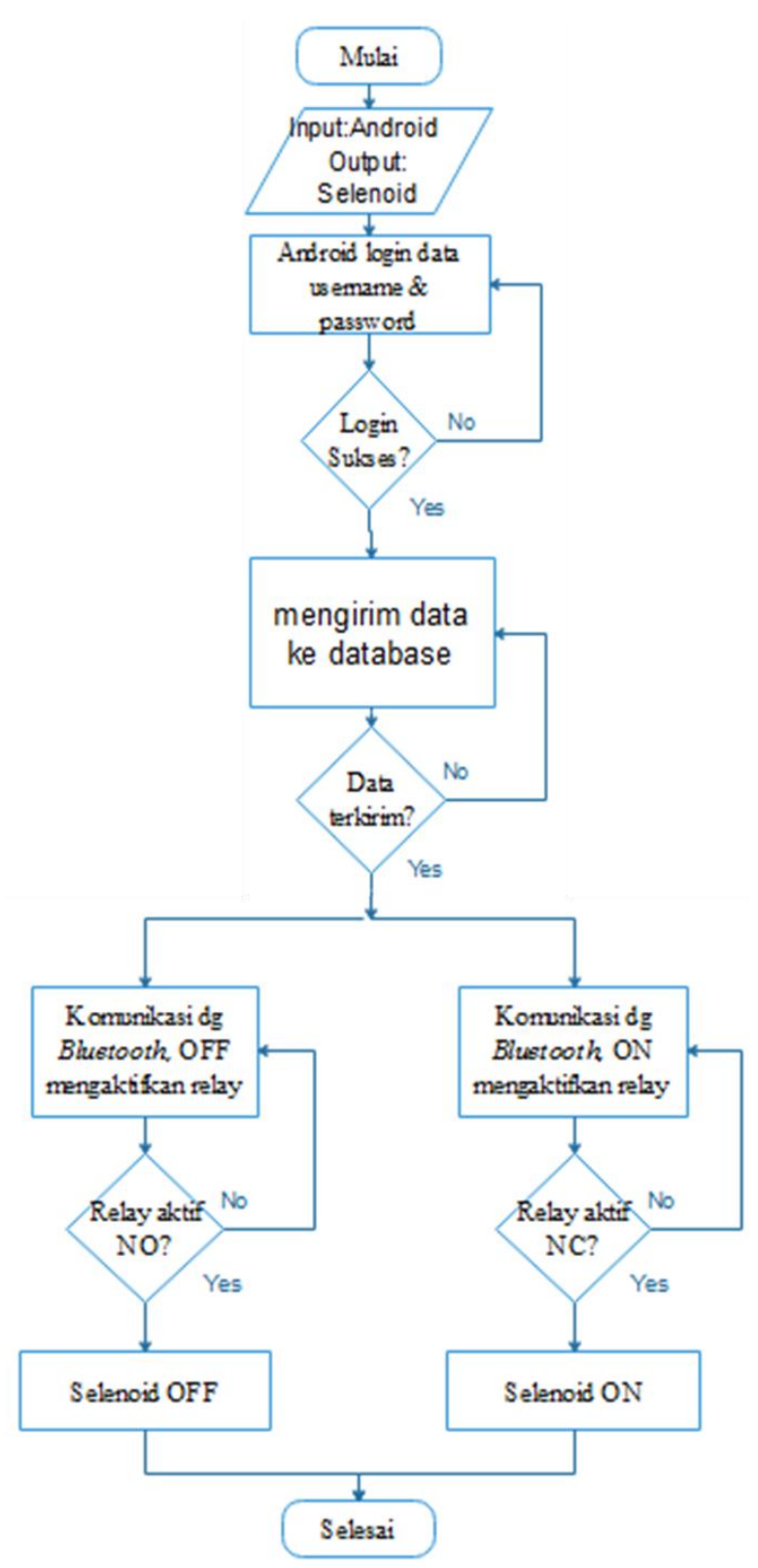

Gambar 4. Diagram alir sistem tempat penyimpanan kotak kunci.

\section{HASIL DAN PEMBAHASAN}

Aplikasi android yang sudah banyak digunakan adalah android studio dan app inventor. Dalam penelitian ini, aplikasi yang digunakan adalah app inventor. Tampilan login pada smartphone android seperti ditunjukkan pada Gambar 5.

Tampilan login terdiri dari username dan password. Jadi, untuk melakukan akses dan menggunakan tempat penyimpanan kunci ini harus registrasi dulu sehingga hanya pengguna yang sudah melakukan registrasi dan disetujui yang bisa mengakses tempat penyimpanan kotak kunci tersebut. Registrasi dan sistem password yang diterapkan ini juga digunakan sebagai pengaman sehingga tidak semua orang bisa akses tempat penyimpanan ini. Sedangkan tampilan home dari smartphone android ditunjukkan pada Gambar 6 . Tampilan home ini terdiri dari nama, nomor induk karyawan (NIK), gender, nomor handphone, and so on.

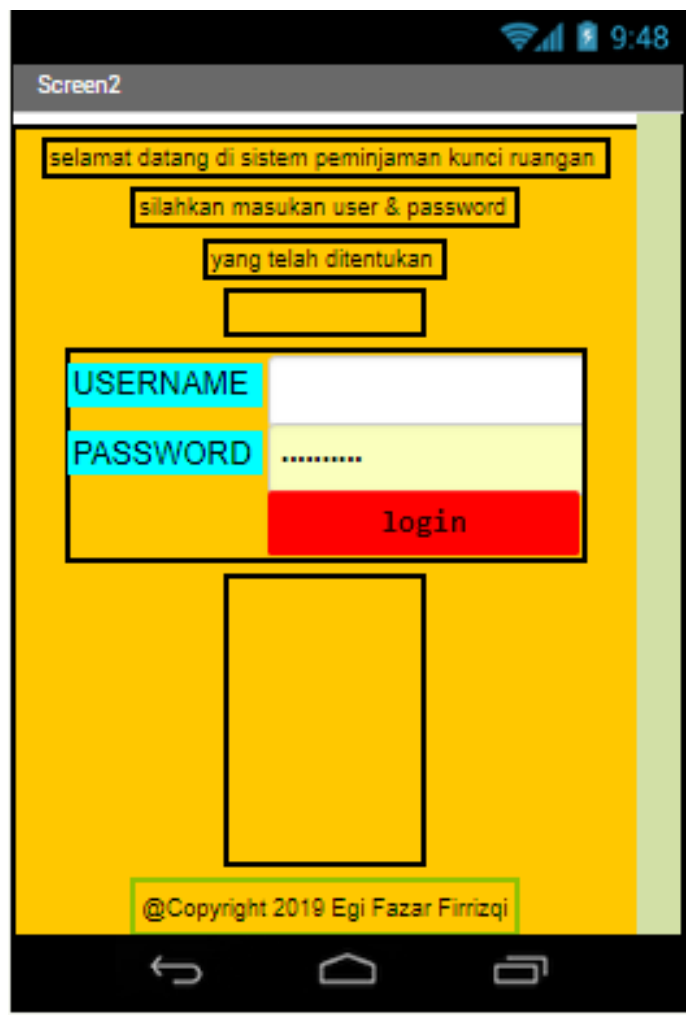

Gambar 5. Tampilan login pada smartphone android.

Sistem komunikasi antara smartphone dan perangkat keras atau sistem kontrol yang ada di kotak kunci dilakukan dengan menggunakan bluetooth. Kemudian data yang masuk ke smartphone di simpan dalam cloud dan bisa diakses melalui jaringan internet sehingga data bisa diakses secara real time di manapun selama ada jaringan internet. 


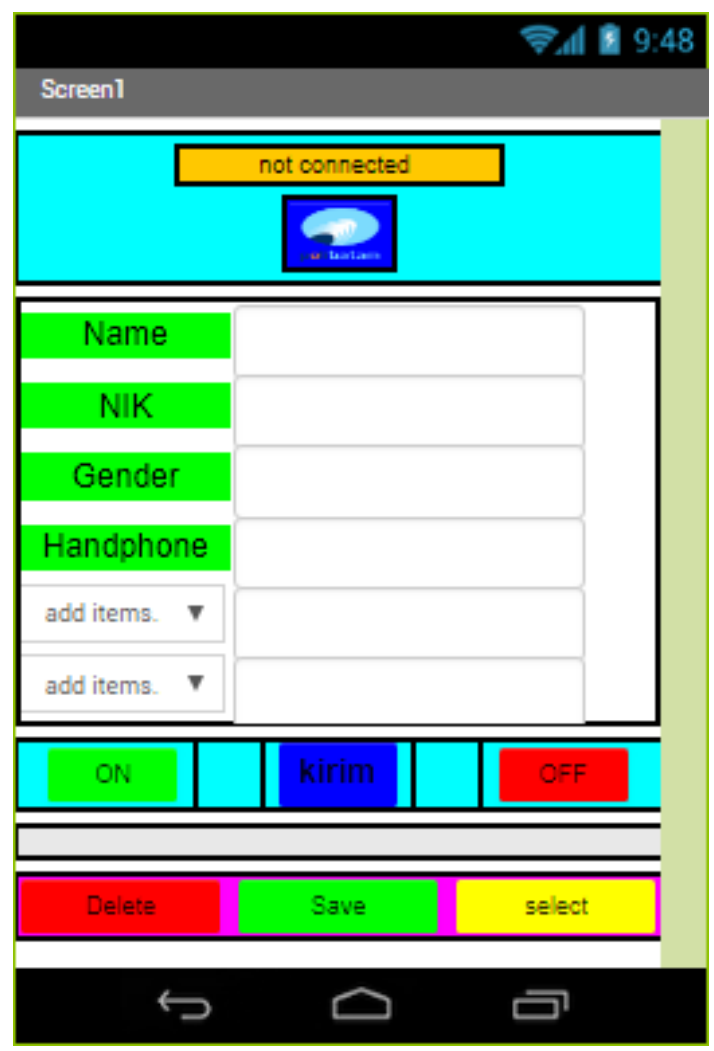

Gambar 6. Tampilan home pada smartphone android

Pengujian aplikasi dilakukan dengan tujuan untuk mengetahui aplikasi yang di gunakan sudah berfungsi dengan baik atau belum. Tabel 1 menunjukkan hasil pengujian keberfungsian aplikasi android yang sudah dibuat. Hasil pengujian menunjukkan bahwa aplikasi android yang dibuat menggunakan app inventor sudah berfungsi dengan baik.

Selain itu, pengujian aplikasi android terhadap perangkat keras yang sudah dibuat (kotak penyimpanan kunci) juga dilakukan. Hasil pengujian ditampilkan secara lengkap pada Tabel 2. Hasil pengujian menunjukkan bahwa aplikasi android sudah berhasil terhubung ke perangkat keras tempat penyimpanan kunci.

Tabel 1. Hasil pengujian fungsi aplikasi android.

\begin{tabular}{|c|l|l|c|}
\hline No & Tombol & \multicolumn{1}{|c|}{ Fungsi } & Status \\
\hline 1 & Login & $\begin{array}{l}\text { Untuk } \\
\text { menginput } \\
\text { username } \\
\text { dan } \\
\text { password }\end{array}$ & Berhasil \\
\hline 2 & save & $\begin{array}{l}\text { Menyimpan } \\
\text { data yang } \\
\text { diberikan }\end{array}$ & Berhasil \\
\hline 3 & Kirim & $\begin{array}{l}\text { Mengirim } \\
\text { data yang di } \\
\text { input kan ke } \\
\text { database }\end{array}$ & Berhasil \\
\hline
\end{tabular}

\begin{tabular}{|c|l|l|l|}
\hline 4 & $\begin{array}{l}\text { Pilih } \\
\text { Bluetooth }\end{array}$ & $\begin{array}{l}\text { Menampilka } \\
\text { n device } \\
\text { Bluetooth }\end{array}$ & Berhasil \\
\hline 5 & ON & $\begin{array}{l}\text { Mengaktifka } \\
\text { n Kontrol } \\
\text { solenoid }\end{array}$ & Berhasil \\
\hline 6 & OFF & $\begin{array}{l}\text { Mengnonakt } \\
\text { ifkan control } \\
\text { solenoid }\end{array}$ & Berhasil \\
\hline 7 & Delete & $\begin{array}{l}\text { Menghapus } \\
\text { data yang } \\
\text { disimpan }\end{array}$ & Berhasil \\
\hline 8 & Select & $\begin{array}{l}\text { Memilih } \\
\text { data yang } \\
\text { disimpan }\end{array}$ & Berhasil \\
\hline
\end{tabular}

Tabel 2. Hasil pengujian aplikasi android terhadap perangkat keras.

\begin{tabular}{|c|c|c|c|}
\hline $\begin{array}{c}\text { Jarak } \\
(\mathrm{m})\end{array}$ & $\begin{array}{c}\text { Jumalah } \\
\text { Percobaan }\end{array}$ & $\begin{array}{c}\text { Kondisi } \\
\text { selonoid }\end{array}$ & Keterangan \\
\hline 3 & $5 \mathrm{x}$ & ON & Berhasil \\
\hline 6 & $5 \mathrm{x}$ & ON & Berhasil \\
\hline 9 & $5 \mathrm{x}$ & ON & Berhasil \\
\hline 12 & $5 \mathrm{x}$ & ON & Berhasil \\
\hline 15 & $5 \mathrm{x}$ & ON & Berhasil \\
\hline
\end{tabular}

Pengujian terhadap tampilan data juga dilakukan. Tampilan data ini bisa diakses menggunakan internet sehingga proses monitoring data bisa dilakukan di mana saja selama ada jaringan internet. Gambar 7 menunjukkan tampilan data pengambilan dan pengembalian kotak kunci di tempat penyimpanan kotak kunci.

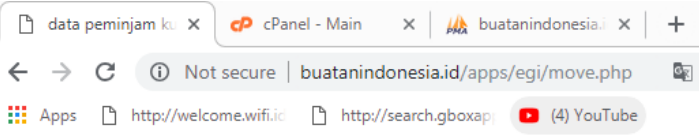

Gambar 7. Tampilan data di website.

Tampilan data yang muncul sesuai dengan data yang dimasukkan saat registrasi di awa seperti nama, NIK, gender, nomor HP, status (mengambil/mengembalikan), ruangan, dan waktu. Data tersebut dapat dilihat dengan membuka link https://buatanindonesia.id/apps/egi/move.php. Data yang ditampilkan merupakan data real time dan berubah sesuai penggunaan aplikasi pada perangkat tempat kunci. 


\section{KESIMPULAN}

Tempat penyimpanan kotak kunci berbasis smartphone android sudah berhasil dibuat. Hasil beberapa pengujian seperti pengujian aplikasi, pengujian aplikasi terhadap perangkat keras, dan pengujian tampilan data di website menunjukkan bahwa sistem sudah berjalan dan berfungsi dengan baik. Hanya dengan membuka website, data pengguna atau pemakai tempat penyimpanan kotak kunci bisa langsung dilihat secara real time.

\section{REFERENSI}

1. Anusuya, M. A., \& Katti, S. K. (2009). Speech Recognition by Machine: A Review. International Journal of Computer Science and Information Security, 6.

2. Kaur, I. (2010). Microcontroller Based Home Automation System With Security. International Journal of Advanced Computer Science and Applications, 1, 60-65.

3. Khan, A., Baharudin, B., Lee, L. H., \& khan, K. (2010). A Review of Machine Learning Algorithms for Text-Documents Classification. Journal of Advances in Information Technology, 1, 4-20.

4. Pahuja, R., \& Kumar, N. (2014). Android Mobile Phone Controlled Bluetooth Robot Using 8051 Microcontroller . International Journal of Scientific Engineering and Research, 2(7), 14-17.

5. Rahadi, D. R. (2014). Pengukuran Usability Sistem Menggunakan Use Questionnaire Pada Aplikasi Android. Jurnal Sistem Informasi , 6, 661-671.

6. Saini, P., \& Kaur, P. (2013). Automatic Speech Recognition: A Review. International Journal of Engineering Trends and Technology, 4(2).

7. Septryanti, A., \& Fitriyanti. (2017). Rancang Bangun Aplikasi Kunci Pintu Otomatis Berbasis Mikrokontroler Arduino Menggunakan Smartphone Android. Journal Of Computer Engineering System And Science, 2, 59-63.

8. Silvia, A. F., Haritman, E., \& Muladi, Y. (2014). Rancang Bangun Akses Kontrol Pintu Gerbang Berbasis Arduino dan Android. Electrans, 13, 1-10.

9. Wang, R., Enck, W., Reeves, D., Zhang, X., Ning, P., Xu, D., et al. (2015). EASEAndroid: Automatic Policy Analysis and Refinement for Security Enhanced Android via Large-Scale Semi-Supervised Learning. The 24th USENIX Security Symposium . Washington: USENIX Association.

10. Yuliza, E., \& Kalsum, T. U. (2015). Alat Keamanan Pintu Brankas Berbasis Sensor Sidik Jari dan Passoword Digital dengan
Menggunakan Mikrokontroler Atmega 16. Jurnal Media Infotama, 11. 